\title{
Discourse Analysis as a Tool for Promoting the 'Critical Literate' VET Teacher
}

\author{
Michael Thoma ${ }^{1,2}$ (iD $\cdot$ Annette Ostendorf ${ }^{1,2}$
}

Received: 23 January 2017 / Accepted: 6 August 2017 /

Published online: 24 August 2017

(C) The Author(s) 2017. This article is an open access publication

\begin{abstract}
The paper deals with the concept of 'Critical Literacy' in the context of VET teacher education. It focuses on the question of whether and how critical literacy can be developed drawing on elements of discourse research. This is illustrated by means of a higher educational setting, dealing with business administration textbook usage and research. The impact of our learning and teaching setting is illustrated via an empirical longitudinal study (three-phase pre-post design) of students doing a master's degree in business education at an Austrian university. Data were initially collected directly before and after the university seminar using a semi-standardised questionnaire $(n=54)$. In order to obtain an insight into the sustainable impact of our discourse analysis course on students' thought and actions, in the third phase of data collection, eight participants, who in the meantime had four months experience in VET schools as student teachers $(120 \mathrm{~h})$ were invited to a qualitative interview. The paper encompasses a theoretical discussion on the concept of critical literacy, applies it to the target group VET teacher students and shows empirical evidence on pros and cons of discourse analytical course design aiming at the critical literate teacher.
\end{abstract}

Keywords Critical literacy · VET teacher education · Discourse analysis, poststructuralism $\cdot$ Textbook analysis

Michael Thoma

michael.thoma@uibk.ac.at

Annette Ostendorf

annette.ostendorf@uibk.ac.at

1 Department of Organisation and Learning, University of Innsbruck, Innsbruck, Austria

2 Fakultät für Betriebswirtschaft, Institut für Organisation und Lernen, Universität Innsbruck, Universitätsstraße 15, A-6020 Innsbruck, Austria 


\section{Introduction}

The ability of individuals to critically reflect on, categorise and assess information, knowledge and the truths they encounter seems to be more important today than ever before. Given the ever-increasing opportunities to experience information, knowledge and truth in a 'postmodern, text-based culture' (Luke and Freebody 1997, p. 47), today's subject is entangled in a web of countless narratives that are often quite contradictory. At the same time, we are faced with the erosion of stable and reliable criteria that might serve as orientation in assessing the quality of these experiences. In the context of a 'crisis of knowledge' (Cilliers 2013), questions arise concerning the production of social stocks of knowledge - or, as Foucault puts it, a 'politics of truth' (Foucault 1992, p. 14) and the 'creation of truth' (Foucault 2005, p. 278) that goes with it. Against the background of this diagnosis of the present, reflective judgement would appear to depend largely on the individual's ability to ask questions to texts in order to examine what the textual material actually does and in what way this is organised. Such ability can be termed critical literacy.

Critical literacy 'involves second guessing, reading against the grain, asking hard and harder questions, seeing underneath, behind, and beyond texts, trying to see and "call" how these texts establish and use power over us, over others, on whose behalf, in whose interests.' (Luke 2004, p. 4)

The promotion of critical literacy as an educational goal focuses in equal measure on the school classroom and teacher education at universities. The present study examines critical literacy in the context of VET (vocational education and training) teacher education and hence as a question of university teaching. Teachers' critically reflective approach to knowledge manifests itself in the classroom context in the selection, reduction and preparation of text-based content and hence the teaching materials structuring it.

The research questions pursued here primarily inquire as to whether and to what extent critical literacy can be promoted in the context of university teaching interventions and how sustained such an impact can be.

The study examines potential VET (upper secondary level) teachers doing master's degrees in 'business education' at an Austrian university. Critically reflective screening, analysis and compilation of textual teaching materials is particularly challenging for these (trainee) teachers, since economic and social science teaching content has great potential for interpretation and its exploitation or neglect can open up or reduce educational opportunities. Promoting economic education (Ökonomische Bildung) which following Beck (1989, p. 591) entails the three dimensions of 'economic thought and knowledge', 'economic attitudes' and the 'capacity for economics-related moral reflection' - thus largely requires diverse perspectives and approaches with which to enable learners to develop a reflective economic worldview. Critical literacy would appear to be of key importance in supporting the creation of multifaceted business economics classes with a focus on diversity and multiple perspectives.

To examine the development of critical literacy of teacher trainees, we focus on the medium of school textbooks that had received state approval for use in business administration teaching at 'higher schools for commerce' (Handelsakademien, ISCED level 4/5). We have selected this medium for two main reasons: firstly, school textbooks and the knowledge they present can be said to represent a specific kind of truthfulness, 
of acceptance as truth. In a way, they translate and render more concrete teaching curricula and hence there is the potential not only for them to shape teaching to a large degree, but also - due to state approval processes - for teachers to uncritically embrace the forms of knowledge they present. Secondly, it can be assumed that school textbooks still play a central role in the overall repertoire of teaching and learning media (Hintermann et al. 2014). Strong reliance on textbooks can certainly be considered typical of the type of school under consideration here (Ostendorf and Thoma 2010). Thus, a critical approach to textbooks would appear to be a crucial didactic skill for teachers, particularly in the sphere of business management.

This paper pursues three aims. It first seeks to interpret the concept of critical literacy with respect to teacher education and hence, closely related to this, considers how critical literacy - as a facet of professional teacher competence - can be promoted in VET teacher education. To this end, we present a university learning and teaching setting we have developed, drawing on procedures of discourse analysis research. The impact of this course on the development of critical literacy is then illustrated via empirical longitudinal data (pre-post design). Our research design goes beyond mere evaluation of the university teaching setting however, since we, thirdly, also examine how sustainable this impact is in the teacher trainees' first substantial teaching experience at school.

\section{Critical Literacy as a Goal of VET Teacher Education: Theoretical Principles}

Critical literacy has been discussed for around three decades in Australian (and to some extent in South American and South African (Marsh et al. 2005)) pedagogic and educational science literature but has hitherto received scant attention in Europe.

Our view on Critical literacy bears reference to the movement of 'New Literacy Studies' (NLS) (e.g. Gee 2000, 2014; Street 2003; Rogers and O'Daniels 2015) emphasizing the situatedness of reading, writing and meaning within social practices and discourses. Activity-based learning on textual material (reading) and the enhancement of knowledge about language are fundamental features of our pedagogical design. However, our research background is not rooted in linguistics - as NLS mainly is - but in business and vocational education research.

Critical literacy can be described as a kind of critically reflective approach with regard to dealing with texts. In contrast to other approaches to literacy, such as 'economic literacy' (e.g. Jappelli 2010), critical literacy is not the preserve of any particular scientific field. Moreover, it must be understood as an integrative crosssectional disposition addressing the ability to reflect on knowledge itself against the background of the interdependence of language, power and identity (Rogers and Mosley Wetzel 2014).

Pedagogy requires the development of critical literacy both in teacher education and in the school classroom. Learners can only be supported in developing critical literacy, however, if teachers themselves have a keen understanding of how to recognise and assess the ways in which knowledge is produced in texts. We hold this to be an important goal of any teacher education programme that seeks to go beyond teaching methodology and a mere reproduction of content. Critical literacy opens a space of 
reflection in which something that is 'other' can be systematically emphasized in order to lend a certain diversity to the encounter between learner and content. Thus, it is an important facet of professional teacher competence.

Our pedagogical work shares the aims with genre-based pedagogy as elaborated by the Sydney School which is grounded in the work of Vygotsky, Halliday and Bernstein. Genre-based pedagogy is designed 'to give teachers the tools they need to overcome the inequality of access, participation and outcomes in their classes.' (Rose and Martin 2012 , p. 6). Furthermore our university didactics are fundamentally indebted to Wolfgang Klafki's (1985) theory of education and critical-constructive didactics. We share his maxim that aspiring teachers must learn to undertake justified selection of educational content, orientated around exemplarity, relevance to the present and the future, content structure and accessibility in connection with 'key problems typical of the epoch'.

However, we reflect on these categories from the perspective of a specific type of science, born of post-structuralist thought that can be labelled discourse theory in the Foucauldian tradition. Against this background, the question of 'determining potential approaches and portrayals' (Klafki 1985, p. 215) becomes more specific, in that teaching and learning materials are reflected in terms of their performativity and are to be examined related to what they actually $d o$ (for instance in relation to modes of classification, attribution, parallelisation, normalisation, problematisation) and what the consequences of these doings are. Insights into the powerful nature of the production of knowledge can then serve to anchor the manifold realisation of learning and teaching situations.

Our discourse theoretical perspective represents a certain updating and expansion of critical-constructive didactics, since sharpening teachers' critical perception in dealing with teaching materials addresses the problem of a 'crisis of knowledge' and is systematically rooted in the context of reflections on lesson type and structure. The figure of the 'critically literate teacher' propagated and described in specific detail below owes much to the above approach to university teaching.

\section{Facets of Critical Literacy}

On the basis of an analysis of the critical literacy literature, Lewison et al. (2002) produced a survey synthesising four dimensions that might shape interpretation of the construct:

- Disrupting the commonplace

- Interrogating multiple viewpoints

- Focusing on socio-political issues

- Taking action and promoting social justice

These dimensions are closely related, but focus on different aspects of content. Let us examine them in closer detail:

Disrupting the commonplace is 'seeing the "everyday" through new lenses' (Lewison et al. 2002, p. 383), which might also be described as seeing what lies behind something. This requires a certain attitude to dealing with textually communicated knowledge, an attitude that is manifested in permitting irritations and embracing a 
certain amount of daring. Disrupting the commonplace thus describes an attitude that questions commonplace and habitual assumptions and convictions and is prepared to leave paths of normality and entertain dissenting thought. 'The disrupting idea that teachers and students need to understand is that no text is neutral' (Vasquez et al. 2013, p. 9) and that 'texts are constructed. Anything that has been constructed can be deconstructed' (Janks 2000, p. 176). Disrupting the commonplace can be stimulated by examining what texts specifically do and the way in which they do it, which assumptions, categorisations and attributions they contain, which structures they take up, in order to produce a certain meaning or invite a certain reading, and which other meanings or readings they thereby exclude. This deconstruction allowing a partiality of perspective is related to another dimension of critical literacy which might be termed Interrogating multiple viewpoints. 'Perspectives shape the world'. 'What we see depends on where we stand' (Rogers and Mosley Wetzel 2014, p. 100). Recognition of one's own perspectival dependence, the keen perception of inclusion and exclusion, hegemonial and marginalised positions in social stocks of knowledge can be considered a prerequisite for the conscious exploration and discovery of other perspectives, ultimately allowing the observer to stand 'in the shoes of others'. Interrogating multiple viewpoints can be interpreted as a vehicle that helps to disrupt 'our tendency to provide easy answers to complex problems' (Vasquez et al. 2013, p. 12). It thus promotes substantial, comprehensive observation and approaching complex phenomena from a broad perspective.

Focussing on socio-political issues as a further dimension of critical literacy is to pay attention 'to how sociopolitical systems, power relationships, and language are intertwined and inseparable' (Lewison et al. 2002, p. 283). The emphasis here is on the interdependence between the assumedly ineluctable connection of language and power and their structuring effect in relation to the socio-political systems of which we are part. Focusing on socio-political issues entails questioning unequal power relationships within social structures. It thus ultimately appeals to an (ethically) democratic-political aspect of thought. Furthermore, critical literacy also has a transformative element; critically literate people are considered 'agents of change' (Janks 2013, p. 229) undertaking specific actions on the basis of the attitudes and insights outlined above, with the aim of achieving social equality (taking action and promoting social justice). Critical literacy thus finds its performative expression in a form of citizenship which aims to realise inclusion, embraces and revisits sensitive orientation towards and consideration of heterogeneity and diversity and can thus be read as work on established and stabilised frameworks of normality including as an act of resistance.

At this point it is essential for our research to specify the comparatively generalised dimensions of critical literacy with respect to the professional tasks of teachers. The following contours of critically literate teachers thus demonstrate the extent to which dimensions of critical literacy can be taken into consideration when designing learning and teaching situations as a core pedagogic activity. Critically literate teachers might be characterised as:

- adopting an attitude of critical-constructive distrust, a reflective distance in the screening, selection and analysis of various forms of textual organised representations of content (Disrupting the commonplace);

- in so doing, paying attention to what the textual material includes and excludes and how meaning is created in this fashion. They use generalisations, limitations and 
marginalisation in the textual material as anchor points for reflection to systematically emphasize something that is 'other' (Interrogating multiple viewpoints);

- recognising the ineluctable connection between language and power and their productive and structuring effects on socioeconomic/political realities (Focusing on socio-political issues); and

- possessing a concept of teaching includes permanent work on the demarcation lines running through established and stabilised frameworks of normality, and their practices of didactic selection, reduction and presentation are oriented around blurring these lines. (Taking action and promoting social justice)

\section{Promoting Critical Literacy - a Discourse Theoretical Approach}

This gives rise to the question of how critical literacy can be developed in teacher students. The theory behind the conception of our university teaching intervention assumes that discourse analysis can contribute to creating critical literacy. This is supported by some of the literature on the subject (Luke 2012; Rogers and Mosley Wetzel 2014).

The version of discourse analysis conceived within the framework of our university teaching intervention and undertaken by the students draws on discourse analytical research approaches from the field of the social sciences in the German-speaking countries, which in turn are informed by the discourse theory of the French philosopher and historian Michel Foucault (esp. Keller 2012; Diaz-Bone 2006). Here we can provide only a very rough outline of three elements of a Foucauldian conception of discourse (for a more detailed description e.g. Ball 2013) following the knowledge-power-subject constellation.

- As a 'group of statements that belong to a single system of formation' (Foucault 1972, p. 107) a discourse displays a certain (repeatable and reconstructable) logic, which, as a deep structure, causes numerous scattered utterances to appear on the surface. Discourses do not provide an innocent, neutral description of a prediscursive and naively experienced reality. Moreover discourses are to be interpreted as productive, reality-constituting factors that provide a specific socio-historically situated knowledge for interpreting the world, and thus supplying the basis for individual and collective consciousness.

- Discursive 'way(s) of worlding, of appropriating the world through knowledge' (Diaz-Bone et al. 2007, p. 4) cannot be separated from power, rather discourses are always shaped by power (Foucault 1983), which initiates, preserves and transforms the way they are structured and create structure.

- As a form of 'underlying structure of human manners of speaking and hence also thinking' (Bührmann and Schneider 2008, p. 25), discourses cannot be intentionally produced, transformed or renewed by individual subjects. Discourses always exist prior to subjects, which are subsumed within them.

Discourse analysis is primarily concerned with texts, since it is texts, as material manifestations of the discursive that allow an analytical approach to discourses.

The discourse analytical research projects of our students in the context of our higher educational setting were directed at the questions of how knowledge of a certain topic, a specific phenomenon (for example leadership, justice, normality, responsibility) is discursively produced in the school textbooks, and what form this knowledge takes. 


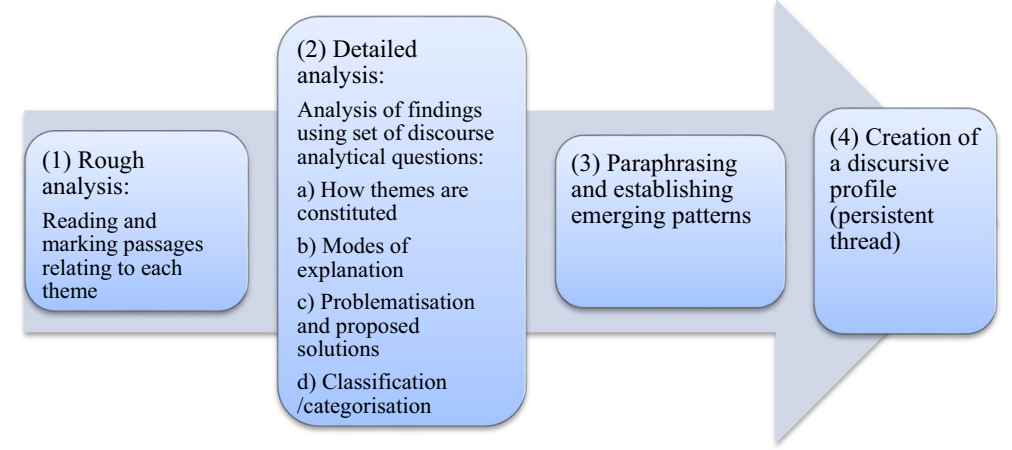

Fig. 1 Four phases of discourse analysis

The task students were set consisted of four steps (cf. Fig. 1): a rough analysis (phase 1) involved the inductive selection and marking of passages relevant to their research question, in order to filter and reduce the material. The next step was a more detailed analysis (phase 2) applying a set of pre-generated heuristic questions to the marked passages. These questions helped to examine the textual material in order to discover what it actually does; they served as reference points for identifying discursive practices in the formation of knowledge. The findings of this close analysis were documented by paraphrasing. In phase 3, this paraphrasing was systematically compared in order to establish whether specific patterns with regard to the examined topic emerge. Phase 4 then entailed the summarizing of the findings in the form of a discursive profile describing the underlying logic of the formation of knowledge. ${ }^{1}$

\section{Outline of the Pedagogical Framework of the Higher Education Learning Arrangement}

Let us now outline the key features of the course design implemented for VET teacher students at an Austrian university to provide context for the empirical data discussed further below.

Duration and credits: 1 semester, 10 ECTS credits

\section{Assumptions regarding participants' anthropogenic conditions}

All the students have acquired knowledge of business management at the bachelor's degree level; they have at least basic knowledge of education and business education, pedagogical content knowledge and skills as part of a master's degree in business education.

$\mathbf{A i m}^{2}$ : Developing participants' critical literacy via discourse analysis

\footnotetext{
${ }^{1}$ For a more precise description of this version of discourse analysis in the context of textbook research see Thoma 2015.

${ }^{2}$ Participants were not directly informed of the goal of developing critical literacy which we have outlined here.
} 
- Students develop the ability and willingness to reflect critically on school textbook knowledge. In doing so, they consider their own attitudes towards this teaching medium per se and their own views and assumptions regarding the nature of the knowledge disseminated by such books (critical-constructive distrust). (Disrupting the commonplace)

- Students recognise the relativity and dependence on perspective and context of (school textbook) knowledge and hence e.g. the importance of multiple perspectives in the content of lessons as a prerequisite of reflective economic education. (Interrogating multiple viewpoints)

- Students recognise the powerful significance of language in texts and its impact in structuring (teachers' own) perception and ways of interpreting socioeconomic realities. (Focusing on socio-political issues)

- Students apply the critical stance acquired during the module to designing their own business management lessons. They integrate political-democratic aims and approaches embracing inclusivity and heterogeneity into their creation of business management learning and teaching situations. (Taking action and promoting social justice)

Methodology: Performative communication of discourse theoretical concepts and project-based analysis of school textbook knowledge through group work; overall we follow the idea of 'scaffolding' in the sense of Vykotsky (1978)

- Students receive an introduction to discourse theory and Foucauldian discourse analysis

- Students undertake a project entailing discourse analysis of textbooks that have received state approval for use in business administration teaching at 'higher schools for commerce', with a five-year duration. The focus is on state-authorised books from the two leading publishers (in terms of circulation). Each of the student groups (12 groups in total, each group consisting of 5 team members) examines around 1300 pages. Analytical attention is directed at the question of how knowledge of a specific topic is produced in the textual material and thereby offers a specific image of reality. Options included:

Images of ...

- danger/threat

- leadership

- normality

- justice

- responsibility

- For their independent projects, the students receive guidelines on the four steps of analysing school textbook knowledge (cf. Fig. 1).

- Students submit a final paper documenting their research process, the results of their analysis and their methodological reflections. The paper also contains consideration of the didactic implications of their analysis. 


\section{Research Design}

We are interested in the impact of the specific design of university teaching based on elements of discourse analysis. The focus is on developing critical literacy in VET teacher students through university learning and teaching arrangements inspired by discourse analysis. This gives rise to the following research questions:

To what extent does a higher educational setting drawing on discourse analysis contribute to the development of VET teacher trainees' critical literacy? How sustained is its impact? Which facets of critical literacy does this entail?

To this end, we chose a three-phase pre-post design rooted in qualitative interpretative logic in terms of its basic underlying methodology but containing quantitative descriptive elements (Fig. 2).

In order to increase the number of participants in our sample, the university teaching intervention was conducted over two consecutive university years (2015 and 2016) with the same didactic design. This gives us a total of $N=59$ students having taken the module.

Data was initially collected using a semi-standardised questionnaire immediately before and after each didactic intervention. This was not based on self-ratings using preformulated items directly measuring the construct of critical literacy; instead we opted for an indirect approach. The questionnaire included inter alia a semantic differential in order to capture respondents' subjective perception of school textbook knowledge and an open question, inviting participants to name and explain quality criteria for textbooks as a teaching medium. The aim here was to establish whether perspectives on textbook knowledge had changed due to work on discourse analysis. In order to guarantee anonymity, we did not collect sociodemographic data (age, gender), but asked the students to use a pseudonym. The response rate of the first collection (pre) stands at 91.52\% $(n=54)$, in the second (post) at $93.22 \%(n=55)$. For 52 cases we have clearly identifiable pre-post sets of data. However, since we were (initially) not interested in intra-individual changes but in impacts on the 'group level', we use all of the assessments for our data analysis.

In the third phase of data collection, we wanted to obtain an insight into the lasting impact of our discourse analysis course on students' thought and actions in the context
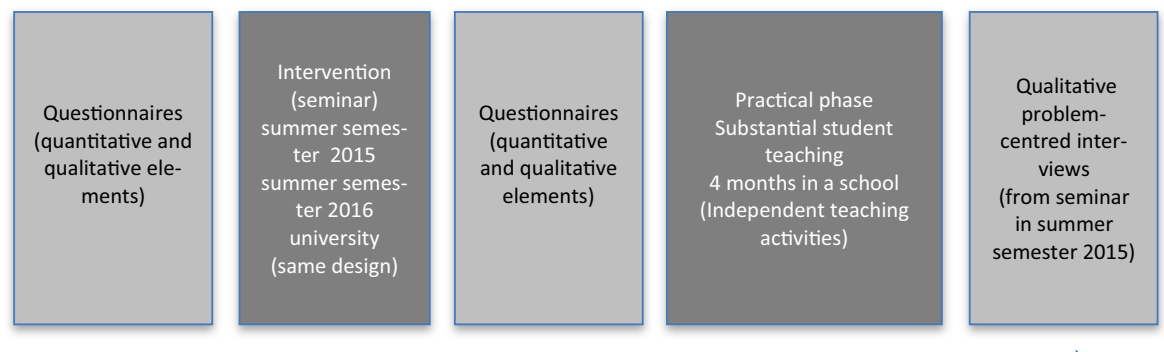

Fig. 2 Longitudinal timeline of methods 
of real classroom practice. Therefore, we conducted qualitative interviews with some of the students who had in the meantime (after the seminar) spent four months in commercial schools (medium and upper secondary level in the Austrian education system, ISCED 3/4/5) teaching business related subjects as student teachers. The completion of this independent teaching experience (around $120 \mathrm{~h}$ ) - which is an obligatory element in the curriculum of our master programme in 'business education' - served us as a criterion for choosing the interview partners. In the period of our data collection, 10 of our students (from the first seminar cohort) had fulfilled this criterion, 8 of them agreed to participate in an interview. The group of interviewees can be regarded as homogenous with respect to their mother tongue (German), their nationality (Austrian) as well as their progress in the masters' study (just before graduation).

The interviews - which were conducted in German - took place a relatively long time after the seminar (approx. 8 months). We know from teacher education research that teaching skills acquired at university cannot be immediately put into practice in day-to-day school teaching. This phenomenon is known as the Konstanzer Wanne (Müller-Fohrbrodt et al. 1978). Resistance in the school culture in which novices find themselves is powerful, and it takes time for them to emancipate themselves from these pressures and tread their own path. Our initial hypothesis prior to the qualitative survey was that it would be difficult to put the critically reflective use of media into practice during student teaching due to such resistance and a fixation with textbooks typical of this type of school.

The eight interviews were transcribed and analysed in two codification processes: a more general one followed by a more specific search for the four dimensions of critical literacy. This entailed systematic and rule-based qualitative content analysis of communication working with symbolic material, governed by theoretical questions and allowing conclusions to be drawn as to the nature of that communication. It was designed to create both greater depth and scope in analysing the aspect of sustained impact. It is a structuring variant of qualitative content analysis that seeks to filter and evaluate certain aspects of the material (Mayring 2008). The four facets of critical literacy theory served as structuring dimensions. We sought to establish a typification via the filtering process; hence the material is structured according to types.

\section{Findings of the Pre-Post Collection}

\section{Semantic Differential}

The students were requested to share their associations regarding business administration textbooks by entering their subjective impressions of diametrically opposed characteristics on a seven-point scale. The graph below displays the mean values $\left(\mathrm{M}_{\text {pre }}\right)$ for $(n=54)$ assessments before (light blue bar) and the mean values $\left(\mathrm{M}_{\text {post }}\right)$ for $(n=55)$ assessments after (dark blue bar)) the didactic intervention. ${ }^{3}$ The bar chart also shows the variations (-/+ one standard deviation of the mean) around the mean values (Fig. 3).

\footnotetext{
${ }^{3}$ The values 1 to 7 (decoded for the statistical analysis) are to be interpreted as follows: $1=$ absolutely significant, 2 = highly significant, 3 = rather significant, $4=$ evenly matched, $5=$ rather insignificant, $6=$ highly insignificant, 7 = absolutely insignificant.
} 


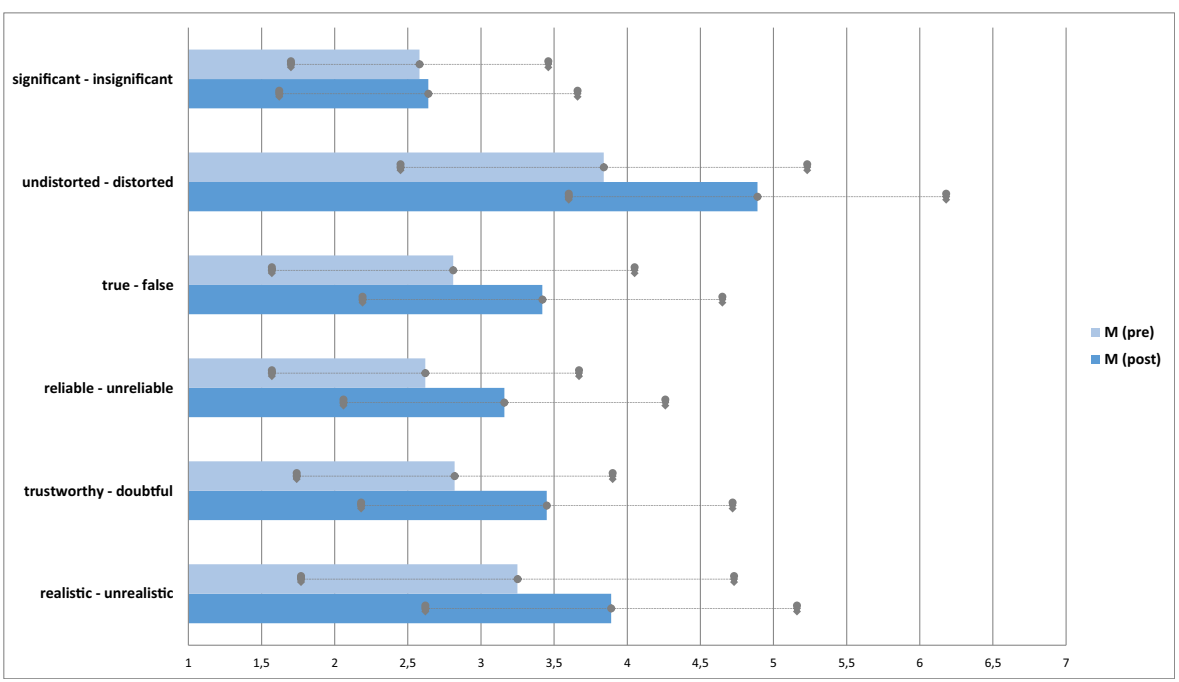

\begin{tabular}{|l|l|l|l|l|l|l|}
\hline & $\begin{array}{l}\text { significant- } \\
\text { insignificant }\end{array}$ & $\begin{array}{l}\text { undistorted- } \\
\text { distorted }\end{array}$ & true-false & reliable-unreliable & $\begin{array}{l}\text { trustworthy- } \\
\text { doubtful }\end{array}$ & realistic- unrealistic \\
\hline M pre, (SD pre) & $2.58,(0.88)$ & $3.84,(1.39)$ & $2.81,(1.24)$ & $2.62,(1.05)$ & $2.82,(1.08)$ & $3.25,(1.48)$ \\
\hline M post, (SD post) & $2.64,(1.02)$ & $4.89,(1.29)$ & $3.42,(1.23)$ & $3.16,(1.10)$ & $3.45,(1.27)$ & $3.89,(1.27)$ \\
\hline
\end{tabular}

Fig. 3 Semantic differential pre-post

Regarding opinions on the significance of textbooks as a teaching medium, the results remain stable if we compare pre- $\left(\mathrm{M}_{\text {pre }}=2.58\right)$ and post-intervention responses $\left(M_{\text {post }}=2.64\right)$. It would thus seem that the seminar setting has not eroded the significance students attach to this medium, even if the results are more scattered in the second set of data $\left(\mathrm{SD}_{\text {pre }}=.88, \mathrm{SD}_{\text {post }}=1.02\right)$. The mean values fluctuate more for pairings directly related to the knowledge the books convey. A comparatively large mean value difference can be observed for the pairing undistorted/distorted. Before the didactic intervention we have a value of $\mathrm{M}_{\text {pre }}=3.84$, after it we have $M_{\text {post }}=4.89$. The mean value difference (1.05) equates to an entire level tending towards 'distorted' with a slight concentration of dispersion measures $\left(\mathrm{SD}_{\text {pre }}=1.39, \mathrm{SD}_{\text {post }}=1.29\right)$. The results vary from a certain uncertainty regarding the degree to which knowledge is distorted to the opinion that textbook knowledge is 'rather distorted'. We can also observe differences in pre-post comparison for the pairing true/false. While textbook knowledge is considered to be 'largely true' both before $\left(\mathrm{M}_{\text {pre }}=2.81, \mathrm{SD}_{\text {pre }}=1.24\right)$ and after $\left(\mathrm{M}_{\text {post }}=3.42, \mathrm{SD}_{\text {post }}=1.23\right)$ the intervention, following the seminar the results drop 0.61 of a point towards 'false', demonstrating a certain, albeit slight, skepsis on the part of students, which is also evident in the changes for the pairings reliable/unreliable $\left(\mathrm{M}_{\text {pre }}=2.62\right.$, $\left.\mathrm{SD}_{\text {pre }}=1.05 ; \mathrm{M}_{\text {post }}=3.16, \mathrm{SD}_{\text {post }}=1.10\right)$ and trustworthy/doubtful $\left(\mathrm{M}_{\text {pre }}=2.83\right.$, $\left.\mathrm{SD}_{\text {pre }}=1.08 ; \mathrm{M}_{\text {post }}=3.45, \mathrm{SD}_{\text {post }}=1.27\right)$. The results for the attributes realistic/ unrealistic show a considerable change: before the invention the students considered textbooks to be 'rather realistic' $\left(\mathrm{M}_{\text {pre }}=3.25, \mathrm{SD}_{\text {pre }}=1.48\right)$, while the 
second set of data shows less certainty, with a shift towards 'unrealistic' $\left(\mathrm{M}_{\text {post }}=3.89, \mathrm{SD}_{\text {post }}=1.27\right)$. With the exception of the pairing 'significantinsignificant', all the mean values on the chart (pre) tend comparatively clearly towards the negative adjectives (post). ${ }^{4}$ Hence, the pre-post results tend overall towards the development of a 'critical-constructive distrust' on the part of respondents regarding textbook knowledge. This distrust appears to be constructive because opinions on the medium's significance remain stable; hence, the medium itself is not rejected outright. The change we have described can be interpreted as a 'critical movement' that provides scope for reflection in which something that is 'other' can be systematically emphasized.

\section{Quality Criteria of School Textbooks}

An open question invited the students to name what they considered to be key quality assessment criteria for textbooks and textbook knowledge and to provide a brief explanation. Each student was asked for five criteria (including an explanation). All the characteristics submitted were then listed (263 criteria pre and 263 criteria post). After filtering out answers that resisted interpretation, ${ }^{5}$ we were left with 484 characteristics ( 243 pre, 241 post) that could be clustered in 17 different categories following several stages of codification. The Holsti index (for two coders) was calculated in order to establish intercoder reliability. The classification agreement stood at .79, which can be considered 'substantial'. For the remainder of the procedure, only those categories with a frequency of $5 \%$ (in relation to the total number of interpretable answers) were included, in accordance with the criteria of consensual naming (Eckes 1994). In each case a cut-off of 12 was employed. The graph below shows the 9 most frequent categories (in descending order of frequency after the didactic intervention in comparison to before) (Fig. 4).

Seven of the nine most frequent categories refer directly to how textbook knowledge is presented, while 'design aspects' (visual elements, use of pictures and illustrations) are related to the books' layout, and 'structure' is concerned primarily with clarity (clear threads, a systematic approach). Before the didactic intervention, the category 'comprehensibility for target group' was logged 47 times. Afterwards, it occurs only 23 times. In this respect, this category displays the largest pre-post discrepancy (a decrease). In the context of our research question, the increases in the categories 'stimulation of critical reflection', 'multiperspectivity' and 'appropriate approach to heterogeneity dimensions' seem particularly interesting.

After discourse analysis, 23 aspects of quality that can be subsumed under the category 'stimulation of critical reflection' are mentioned. Before the didactic intervention, this criterion was only mentioned once. In each case, descriptions were codified relating to knowledge formation, the critical presentation of content or facets aimed at promoting independent thinking in pupils.

\footnotetext{
${ }^{4}$ For comparison: we have also requested 30 further master students (as a kind of control group) to share their associations regarding business administration textbooks on the semantic differential at two different points $\left(t_{1}\right.$, $t_{2}$ ) with an interval of 3 months. The mean values of the assessments $\left(t_{2}\right)$ in comparison to $t_{1}$ remain comparatively stable with a slight, but continuous tendency towards the 'positive' adjectives.

5 This was the case if a single concept was mentioned without further explanation and it was not clear which characteristic was meant. For instance, some respondents simply wrote 'content'. Without further elaboration, this answer cannot be included in our analysis.
} 


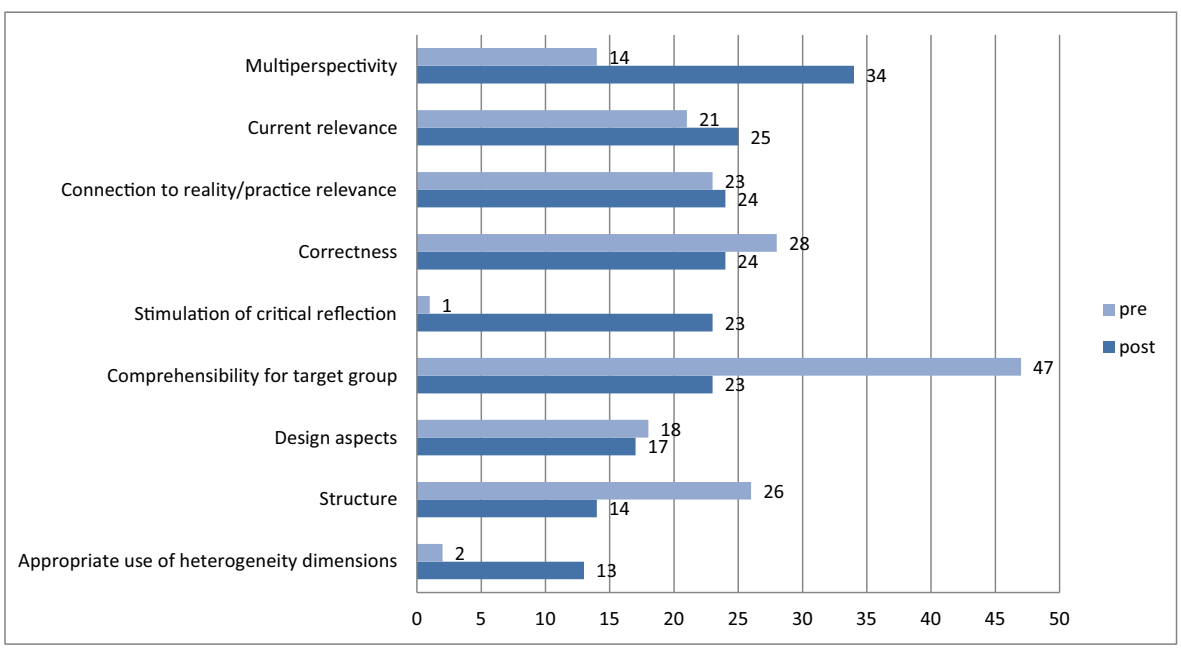

Fig. 4 Frequency of quality categories

Further, after the intervention, 'multiperspectivity' of knowledge is the main quality criterion, with 34 mentions. Codification subsumed all answers suggesting that textbooks should provide various viewpoints, holistic portrayals, a variety of contexts and shifts in perspective and promote the networking of knowledge.

The text's approach to heterogeneity dimensions (esp. experience of migration/ ethnicity, gender) also receives more emphasis after the intervention (13 mentions). This subsumes aspects relating to the presentation of dimensions of heterogeneity free from stereotypes and prejudice or the appropriate reflection of social realities characterised by pluralism and diversity.

\section{Qualitative Survey Results Following the Student Teaching Period at School}

Disrupting the commonplace is clearly supported by the qualitative empirical data. The responses also displayed various kinds of disruption that can be taxonomically classified as affectedness. They range from no disruption at all to content-related, generally questioning disruption, and disruption that transforms perspectives, on two levels - in relation to textbook knowledge itself and in relation to texts in general. Table 1 shows the different features and anchor examples related to the category 'disrupting the commonplace'. A taxonomy of disruption levels is built to differentiate between the modes of disruption in more detail. The range goes from no change to a very deep transformation.

The characteristics of this dimension range from 'none' (level 1) to 'massive' (level $5)$. This indicates that the manifestation of critical literacy can be described not only via characteristics, but also via taxonomy.

In our intervention design we were able to create higher levels of disrupting the commonplace. This is all the more astounding when one considers that textbooks were used extensively in classroom teaching in particular and that students also had to contend with resistance. 


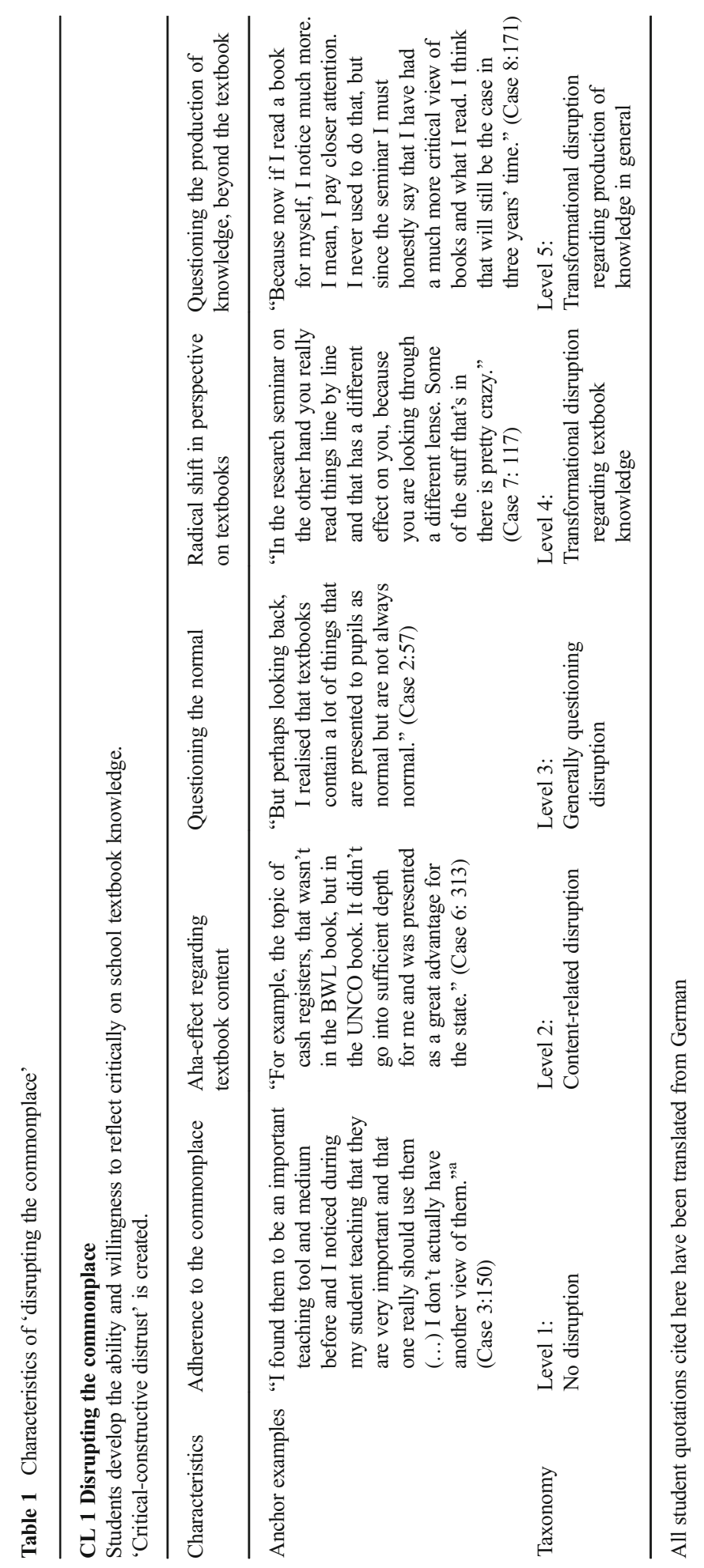


'But we also had a lot of arguments with her [the mentor teacher] because we said we would like to make more use of the internet or new media. She simply couldn't understand that, since the textbook was the most important thing and the most important things were in it, and it was the best way to communicate them to the pupils.' (Case 8:31)

For the dimensions interrogating multiple viewpoints and focusing on sociopolitical issues, it was difficult to establish differences or a hierarchy. There was a focus on unbiased language and a clear intention to enlighten pupils. It was also evident that lasting awareness of the use of language had been created. Respondents often mentioned language mechanisms of inclusion and exclusion and attempted to redress the balance in their own teaching activities. While they present different narratives regarding the facets of these dimensions, it can be assumed that the impact of the didactic interventions was lasting. Table 2 describes the dimension 'interrogating multiple viewpoints' and 'focusing on socio-political issues' showing facets within these dimensions of critical literacy.

Language is definitely seen as a semantic system influencing perception. Statements on the context in which books are produced refer mainly to an intention to enlighten pupils rather than questioning the socio-political framework of textbook knowledge.

Table 2 Facets of 'interrogating multiple viewpoints' / 'focusing on socio-political issues'

\section{2 Interrogating multiple viewpoints}

Students recognise the relativity and context dependence of (school textbook) knowledge

\section{3 Focusing on socio-political issues}

Students recognise the powerful (inclusive and exclusive) significance of language in texts and how they structure perception and interpretation of socioeconomic realities

$\begin{array}{ll}\text { Characteristics } & \begin{array}{l}\text { Recognising stereotypes and exposing } \\ \text { hidden messages }\end{array}\end{array}$

Anchor examples Because it's like that, men always have the good jobs. And if a woman is a boss somewhere, then it's because her father has taken over the company. I well remember this role of men and women and also the role of foreign countries, because the chapter on foreign trade is just nasty. Like, you shouldn't trade with foreign countries at all. That's how it comes over in the book. And foreigners themselves, well they're either taxi drivers or doormen or have a food stand. And when I think about it now, at school I really noticed we have a lot of pupils with a migration background and in the books there are only ever Austrian names." (Case 7: 81)

Condensation Demanding unbiased language
"Well for me it would be important - I didn't think I would find it so important at first to communicate to the pupils how such a textbook is produced. That is, that it isn't something that someone simply thinks up. But that there are laws behind it and that they are building on them. And then I would also say that not everything that is in the textbook is right. You can also do research and look for things and not just use the textbook as the only medium" (Case 2: 141)

Intention to enlighten 
Table 3 Facets of 'taking action (and promoting social justice)'

CL 4 Taking action (and promoting social justice)

Students are able to apply the critical stance acquired during the module to designing their own business management lessons.

\begin{tabular}{|c|c|c|}
\hline Characteristics & Introducing various viewpoints & Blurring the lines of 'normality' \\
\hline Anchor example & $\begin{array}{l}\text { "I took great care, especially as it was a girls' } \\
\text { school, to make sure it was the woman } \\
\text { who ventures into starting a business. } \\
\text { That came very much from the research } \\
\text { on textbooks. It was also the case with } \\
\text { the worksheets, since in the book it was } \\
\text { usually the men who did it and for the } \\
\text { worksheets I usually had women starting } \\
\text { a business" (Case 7: 221)“" }\end{array}$ & $\begin{array}{l}\text { “.. and my strategy was then to try to } \\
\text { include as much as possible. To have a } \\
\text { young person approach an old person, to } \\
\text { have a young person whose parents are } \\
\text { from Turkey approach a grandmother } \\
\text { from Yugoslavia. To bring people } \\
\text { together, on paper and by other means. } \\
\text { Or for example in the case of political } \\
\text { topics, when I thought them to be } \\
\text { political topics, politically relevant } \\
\text { topics, I tried to speak about them with } \\
\text { the pupils openly." (Case 5: 156) }\end{array}$ \\
\hline Condensation & Diversity & Unbiased language, wide diversity \\
\hline
\end{tabular}

In the case of the dimension taking action (and promoting social justice), it is clear that all respondents undertook compensatory measures to redress the balance with respect to use of textbooks. An important issue for all of them was promoting diversity and the use of unbiased language in portrayals and examples. Table 3 illustrates students' ability to transfer their course experiences to real teaching situations. Introducing various viewpoints and blurring the lines of 'normality' get very important for their own business management lessons created in their internship.

The students displayed a variety of strategies for supplementing textbooks with other media such as worksheets, online research, further specialist books and relevant online tools. They acted out of pedagogic responsibility, on which they had come to reflect due to the course. What was most evident was the attitude of doing justice to a plural society.

\section{Concluding Discussion of Empirical Findings}

The findings of the semi-standardised questionnaires indicate that our respondents' view of textbook knowledge was transformed at least temporarily (under the fresh impression of our didactic intervention). They became especially aware of textual mechanisms of inclusion and exclusion and their potential effects (interrogating multiple viewpoints) in combination with an acquired attitude of critical-constructive distrust (disrupting the commonplace). There is less evidence of insights into the logic of discourse formation organising the problematised knowledge on the deep structural level (focusing on socio-political issues). The interview data also clearly suggests that facets of critical literacy were promoted in the students, leading to a differentiation of the dimensions as described in the literature. The qualitative empirical data also clearly demonstrates that the students' view on textbook knowledge underwent sustained transformation. In the first codification process, a total of 31 passages of text were allocated to this aspect. 
Our initial hypothesis that the established routines of classroom practice (the Konstanzer Wanne phenomenon) would prove an obstacle to the sustained performance of critical literacy was not confirmed. To this extent, we can tentatively assume that the discourse analytical intervention fostered the development of a lasting disposition, albeit not to the same degree or intensity in all students.

There is, then, no one single figure of the critically literate teacher; rather, there are different variants that may be described in a spectrum of 'figures' displaying the attitudes that emerge from our qualitative empirical data, arranged according to the 'strength' of their critical literacy. These figures can labelled as follows: a) staunch fans of textbooks, b) differentiating users of textbooks, c) pupil-oriented content-critical pragmatists, d) critical pedagogues, e) humanist critical pragmatists, and f) critical emancipated users of textbooks displaying long-term disruption.

In our sample, there was only one case of a complete absence of critical literacy. More than half (five) of the respondents can be allocated to the 'critical labels' (d, e, f), three of them even to category f) reporting strong disruptions.

It was also evident that the discourse analytical design allowed a form of 'nonnormative' criticism in that respondents did not engage in 'textbook bashing' or criticising the authors, but to an extent recognised the logic of their production. Recognising this logic of production, students were then able to include their own moral and ethical ideas in their teaching decisions. This often related to ideas of justice and avoiding bias (cf. anchor examples in Tables 2 and 3).

The respondents' reactions are strongly connected to the specific material however. It is not clear to what extent they transfer these skills to other texts - or to deeper mechanisms of social knowledge production (knowledge about knowledge) as a whole. There are nevertheless positive indications that critical literacy is transferred from one context to another:

\section{'And now that I really know about it, because we've looked at it for half a year-I simply notice it. I notice it in the newspaper or elsewhere. That is, since the analysis of textbooks I pay much more attention when reading.' (Case 8:79)}

A certain emancipation concerning the use of textbooks in the day-to-day of student teaching was established for almost all eight students in the post-interviews. In spite of a school environment in which the textbook is firmly entrenched and serves as a secret curriculum, it was possible to promote a productive critical distance that gave rise to student teachers' own didactic combinations both embracing and going beyond the medium.

\section{Reflective Review and Outlook}

The data collected indicate that we were able to promote critical literacy with respect to textbook knowledge in this particular teacher education setting. We were able to anchor lasting interruption of the unquestioning use of textbooks as the basis of learning and teaching in vocational education and the development of reflective multiperspectivity. Nevertheless, we acknowledge that the implementation and results of the intervention also presented some challenges. The teacher education design is very complex and required a high level of prior engagement with post-structuralist thought on the part of the trainers. It was particularly difficult to combine the 'language world' of discourse 
theoretical research with that of the students. In the supplementary lecture, students were also introduced to the post-structuralist background, but it remains uncertain how deep an understanding is necessary or indeed possible. On a related note, it should be stressed that while almost all students recognised the need to take a critical view of textbook knowledge, only a few demonstrated new thinking on the level of the logics of discourse formation.

Nevertheless, particularly the statements of the eight students following their own intensive student teaching encourage further efforts to use discourse analysis as a means of promoting critical literacy as part of VET teacher education. Almost all students demonstrated a much more critical attitude towards textual teaching material, translated it into new didactic strategies applied to a specific context. They demonstrated a sustained new reading of textbooks. This new reading provides (aspiring) teachers with a new way of determining their potential approach to and presentation of lesson content, and at the same time they develop for themselves 'categorial educational impulses', in that this new reading can also help them to show critical thinking in other contexts in a 'postmodern, text-based culture'.

Due to the relatively small sample size, the results of the pre-post study presented are more of an illustrative nature. Further empirical research is necessary, particularly in order to support the six figures of critical literate VET teachers with more empirical evidence. Besides, it would be of interest to examine if our graduates (in their roles as future teachers) foster their own students' ability to ask questions to texts, to problematize texts and thus support them in developing critical literacy as well.

Acknowledgements Open access funding provided by University of Innsbruck and Medical University of Innsbruck.

Open Access This article is distributed under the terms of the Creative Commons Attribution 4.0 International License (http://creativecommons.org/licenses/by/4.0/), which permits unrestricted use, distribution, and reproduction in any medium, provided you give appropriate credit to the original author(s) and the source, provide a link to the Creative Commons license, and indicate if changes were made.

\section{References}

Ball, S. J. (2013). Foucault, power, and education. New York/London: Routledge.

Beck, K. (1989). "Ökonomische Bildung" - zur Anatomie eines wirtschaftspädagogischen Begriffs. Zeitschrift für Berufs- und Wirtschaftspädagogik, 85, 579-598.

Bührmann, A., \& Schneider, W. (2008). Vom Diskurs zum Dispositiv. Eine Einführung in die Dispositivanalyse. Bielefeld: transcript.

Cilliers, P. (2013). A crisis of knowledge: Complexity, understanding and the problem of responsible action. In P. Derkx \& H. Kunneman (Eds.), Genomics and democracy (pp. 37-60). Amsterdam/New York: Rodopi.

Diaz-Bone, R. (2006). Zur Methodologisierung der Foucaultschen Diskursanalyse. Forum: Qualitative Social Research, 7(1), §6.

Diaz-Bone, R., Bührmann, A., Rodriguez, E., Schneider, W., Kendall, G., \& Tirado, F. (2007). The field of Foucaultian discourse analysis. Forum: Qualitative Social Research, $8(2), \S 30$.

Eckes, T. (1994). Explorations in gender cognition: Content and structure of female and male subtypes. Social Cognition, 12(1), 37-60.

Foucault, M. (1972). The archaeology of knowledge and the discourse on language (trans: Sheridan Smith, A.M.). New York: Pantheon.

Foucault, M. (1983). Der Wille zum Wissen. Sexualität und Wahrheit. Frankfurt am Main: Suhrkamp.

Foucault, M. (1992). Was ist Kritik? Berlin: Merve. 
Foucault, M. (2005). Subjekt und Macht. In D. Defert \& F. Ewald (Eds.), Michel Foucault. Dits et Ecrits IV (pp. 269-294). Frankfurt/Main: Suhrkamp.

Gee, J. P. (2000). The new literacy studies: from 'socially situated' to the work of the social. In D. Barton, M. Hamilton, \& R. Ivanic (Eds.), Situated literacies: reading and writing in context (pp. 180-196). London: Routledge.

Gee, J. P. (2014). Discourse and "the new literacy studies". In J. P. Gee \& M. Handford (Eds.), The Routledge handbook of discourse analysis (pp. 371-382). London: Routledge.

Hintermann, C., Markom, C., \& Weinhäupl, H. (2014). Debating migration in textbooks and classrooms in Austria. Journal of Educational Media, Memory and Society, 6(1), 79-106.

Janks, H. (2000). Domination, access, diversity and design: a synthesis model for critical literacy education. Educational Review, 52(2), 175-186.

Janks, H. (2013). Critical literacy in teaching and research. Education Inquiry., 4(2), 225-242.

Jappelli, T. (2010). Economic literacy: an international comparison. The Economic Journal. doi:10.1111 j.1468-0297.2010.02397.

Keller, R. (2012). Doing discourse research. London: Sage.

Klafki, W. (1985). Neue Studien zur Bildungstheorie und Didaktik. Weinheim/Basel: Beltz Verlag.

Lewison, M., Flint, A., \& Van Sluys, K. (2002). Taking on critical literacy. The journey of newcomers and novices. Language Arts, 79(5), 382-392.

Luke, A. (2004). Foreword. In M. McLaughlin \& G. DeVoogd (Eds.), Critical literacy: enhancing students' comprehension of text (pp. 4-5). NY: ScholasticInc.

Luke, A. (2012). Critical literacy: foundational notes. Theory Into Practice. doi:10.1080 /00405841.2012.636324.

Luke, A., \& Freebody, P. (1997). Shaping the social practices of reading. In S. Muspratt, A. Luke, \& P. Freebody (Eds.), Constructing critical literacies: teaching and learning textual practice (pp. 185-224). Cresskill: Hampton Press.

Marsh, J., Larson, J., Vasquez, V., \& Comber, B. (2005). Critical literacy. In J. Larson \& J. Marsh (Eds.), Making literacy real: theories and practices for learning and teaching (pp. 40-67). London: SAGE Publications.

Mayring, P. (2008). Qualitative Inhaltsanalyse. Grundlagen und Techniken. Weinheim/Basel: Beltz.

Müller-Fohrbrodt, G., Cloetta, B., \& Dann, H.-D. (1978). Der Praxisschock bei jungen Lehrern. FormenUrsachen - Folgerungen. Stuttgart: Klett.

Ostendorf, A., Thoma, M. (2010). Das Bild der Organisation und die Organisation des Bildes - Ein Beitrag zu einer poststrukturalistisch orientierten Schulbuchforschung. Zeitschrift für Berufs- und Wirtschaftspädagogik, 106(2), 240-257.

Rogers, R., \& Mosley Wetzel, M. (2014). Designing critical literacy education through critical discourse analysis. New York and London: Routledge.

Rogers, R., \& O'Daniels, K. (2015). Critical literacy education: a kaleidoscopic view of the field. In J. Rowsell \& K. Pahl (Eds.), The Routledge handbook of literacy studies (pp. 62-78). New York: Routledge.

Rose, D., \& Martin, J. R. (2012). Learning to write, reading to learn. Genre, knowledge and pedagogy in the Sydney school. Sheffield: Equinox.

Street, B. (2003). What's "new" in new literacy studies? Critical approaches to literacy in theory and practice. Current Issues in Comparative Education, 5(2), 77-91.

Thoma, M. (2015). Critical analysis of textbooks: knowledge-generating logics and the emerging image of 'global economic contexts. doi:10.1080/17508487.2015.1111248.

Vasquez, V., Tate, S., \& Harste, J. (2013). Negotiating critical literacies with teachers. New York and London: Routledge.

Vykotsky, L. S. (1978). Mind in society. The development of higher psychological processes. Cambridge: Harvard University Press.

Michael Thoma (born 1976) currently holds a position as an Assistant Professor in the area of Business Education in the School of Management, Department of Organisation and Learning, University of Innsbruck (Austria). He received his PhD (Dr. rer. soc. oec) in 2010. His research interest is focused on textbook-analysis from a post-structuralist (Foucauldian) perspective.

Annette Ostendorf (born 1965) is a full Professor for Business Education, Head of Department, University of Innsbruck, School of Management, Department of Organisation and Learning. She received her PhD (Dr. oec. publ.) in 1993. Her research interests are focused on vocational competence development, textbook research, connectivity between different learning sites. 